\title{
Effects of tumor growth on taste-aversion learning produced by antitumor drugs in the rat
}

\author{
ILENE L. BERNSTEIN, MICHAEL V. VITIELLO, and RONALD A. SIGMUNDI \\ University of Washington, Seattle, Washington 98195
}

\begin{abstract}
A number of commonly used antitumor drugs (Cytoxan, Adriamycin, cytosine arabinoside, Vincristine) were evaluated for their ability to act as unconditioned stimuli (USs) in a taste aversion conditioning paradigm. With one exception (cytosine arabinoside), discussed in the text, drugs which induce nausea and vomiting when administered to humans (Cytoxan, Adriamycin) produced significant saccharin aversions in rats; a drug which does not produce these symptoms (Vincristine) did not produce saccharin aversions. In later studies, the effect of $u$ chronic disease state (tumor growth) on the acquisition of learned taste aversions was evaluated. Rats bearing moderate or advanced transplantable tumors were comparable to healthy controls in their formation of conditioned taste aversions. Therefore, the chronic malaise produced by a growing tumor neither attenuated nor exaggerated the taste aversions induced by Cytoxan or Adriamycin injections. Results are discussed in terms of their implications for human taste aversion learning.
\end{abstract}

Conditioned taste aversions have been detected following the administration of a wide variety of drugs (see Riley \& Baril, 1976). One drug frequently employed in taste-aversion experiments, the alkylating agent cyclophosphamide (Cytoxan) (Garcia, Ervin, \& Koelling, 1967; Garcia, Hankins, Robinson, \& Vogt, 1972; Wilcoxin, Dragoin, \& Kral, 1971), is presumably effective because it produces symptoms of GI discomfort (i.e., nausea; emesis). Cytoxan is also one of several chemotherapeutic drugs with similar side effects [gastrointestinal (GI) toxicity] which are widely used clinically in the treatment of neoplastic diseases (Goodman \& Gilman, 1970). This suggested that patients receiving treatment for certain types of cancer might form aversions to foods consumed before such treatments.

Bernstein (1978) recently tested this hypothesis and reported that pediatric cancer patients developed significant aversions to a novel ice cream flavor when it was consumed prior to GI toxic drug treatments. These aversions were long-lasting and were evident even though patients had received numerous prior drug exposures. Since drug preexposure is known to attenuate or eliminate taste-aversion conditioning in the rat (Elkins, 1974; Goudie, Taylor, \& Atherton, 1975), the observation of these taste aversions in cancer patients was somewhat surprising. It suggested

Supported by Grant RO1 CA26419-01 awarded by the National Cancer Institute, DHEW. Tumors were provided by Dr. I. D. Bernstein of the Fred Hutchinson Cancer Research Institute, Seattle, Washington. Address reprint requests to: Ilene L. Bernstein, Department of Psychology NI-25, University of Washington, Seattle, Washington 98195. that humans may be particularly susceptible to forming learned taste aversions. On the other hand, it is possible that susceptibility to forming learned taste aversions is limited to the clinical population studied, and not to all humans. Little is known about the effect of a chronic disease state, such as tumor growth, on the acquisition of learned taste aversions. The chronic malaise produced by a growing tumor could (1) sensitize organisms and amplify tasteaversion learning, (2) mask the aversive effects of the US and attenuate taste-aversion learning, or (3) have no effect. The present studies were aimed at investigating this question. The first studies examined normal rats to determine whether a variety of antitumor agents, administered in dosages similar to those in clinical use, would act as USs in tasteaversion conditioning. Later studies compared the taste-aversion learning of healthy rats and rats bearing transplantable tumors.

\section{EXPERIMENT 1}

The drugs tested were Cytoxan, doxirubicin (Adriamycin, an antibiotic), cytosine arabinoside (a pyramidine analog antimetabolite), and Vincristine (a vinca alkaloid.) These drugs, with the exception of Vincristine, produce considerable nausea and vomiting when administered to humans (Goodman \& Gilman, 1970).

\section{Method}

Experiment 1a. Thirty, naive, syngeneic Wistar-Furth (W/Fu) male rats were housed in individual stainless steel cages with free 


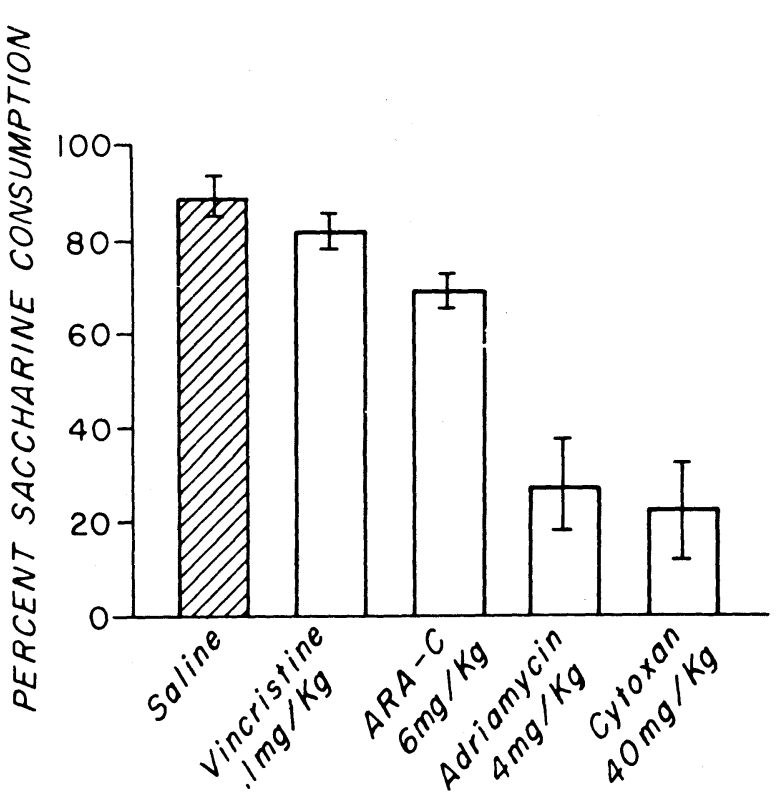

Figure 1. Percent saccharin (saccharin/total fluid $\times 100$ ) consumed during two-bottle preference test as a function of drug treatment. Mean total fluid consumption in preference test: saline $=16.3 \mathrm{ml}$; Vincristine $=14.7 \mathrm{ml}$; ARA-C (cytosine arabinoside) $=16.3 \mathrm{ml}$; Adriamycin $=15.3 \mathrm{ml}$; Cytoxan $=13.8 \mathrm{ml}$.

access to Purina Rat Chow throughout the experiment. This strain of rats readily accepts tumor transplants from other individuals of the same strain, as used in Experiment 2. The animals were divided randomly into five groups. For 12 days, all rats received water for only $30 \mathrm{~min}$ a day. Water was presented in graduated drinking tubes at the front of the cage. The position of the drinking tube was alternated each day. On the 13th day, all rats received a $.1 \%$ aqueous solution of sodium saccharin instead of water, during the usual 30-min drinking session. Immediately after the 30 -min drinking session, each rat was injected intraperitoneally (IP) with one of the following solutions: physiological saline $(1 \mathrm{ml} / \mathrm{kg})$; Cytoxan $(40 \mathrm{mg} / \mathrm{kg})$ (a gift of Keith Wheeler, Mead Johnson);Vincristine (.10 mg/kg); Adriamycin $(4.0 \mathrm{mg} / \mathrm{kg}$ ) (a gift of Luigi Lenaz, Adria Laboratories); or cytosine arabinoside $(6.0 \mathrm{mg} / \mathrm{kg})$. Dosages were converted on a $\mathrm{mg} / \mathrm{kg}$ basis from human therapeutic dosages (Goodman \& Gilman, 1970). Dosages given the rats were twice the typical human dose in an effort to compensate for differences in both route of administration (clinically these drugs are administered intravenously) and metabolic rate. On the 14th day, all rats were given a 30 -min choice between $.1 \%$ saccharine solution and tap water, placed randomly in the right and left positions on each animal's cage. A forced sampling procedure was used in which the rats sampled each solution for at least $10 \mathrm{sec}$ at the beginning of the 30 -min drinking bout while the other tube was briefly removed. Following this procedure, the animals had free access to both solutions for the remainder of their 30-min bout. Preference scores were calculated for each rat by dividing the volume of intake of saccharine solution by the total volume of intake during the 30 -min preference test.

Experiment 1b. Thirty additional rats were exposed to taste aversion conditioning as in the previous study with the addition of two water-drug control groups. Three groups were similar to those in the previous study, with animals exposed to saccharine solution and injected with physiological saline (saccharin-saline group); Cytoxan ( $20 \mathrm{mg} / \mathrm{kg}$ ) (saccharin-Cytoxan group), or Adriamycin (saccharin-Adriamycin group). Two additional groups were exposed to plain tap water prior to being injected with either Cytoxan ( $20 \mathrm{mg} / \mathrm{kg}$ ) (water-Cytoxan group) or Adriamycin ( $4 \mathrm{mg} / \mathrm{kg}$ ) (water-Adriamycin group). All other procedures were the same as described in Experiment 1a.

\section{Results}

Experiment 1a. Results of the preference test are depicted in Figure 1. Control rats which received saline injections during conditioning had an overwhelming preference for the saccharin solution. The overall effect of drug treatments on saccharin preference was significant [ANOVA, $F(4,25)=19.8, \mathrm{p}<$ $.005]$. An analysis of the difference between control intakes and each treatment mean (Edwards, 1972, p. 149) indicated a significant depression of saccharin preference in animals that received a single IP injection of Adriamycin $(p<.01)$ or Cytoxan $(p<.01)$. Saccharin preference after cytosine arabinoside appears somewhat reduced, but this difference is not significant $(p<.10)$. Vincristine injections did not affect saccharin consumption.

Experiment 1b. Results of the preference test are depicted in Figure 2. Control groups (saccharin-saline, water-Cytoxan, and water-Adriamycin) had higher preferences for the saccharin solution than did the experimental groups, which had consumed saccharin prior to either Cytoxan or Adriamycin injections. An analysis of variance indicated a significant overall effect of conditioning treatment $[F(4,25)=25.37$, $\mathrm{p}<.01]$. Planned comparisons confirm that the dif-

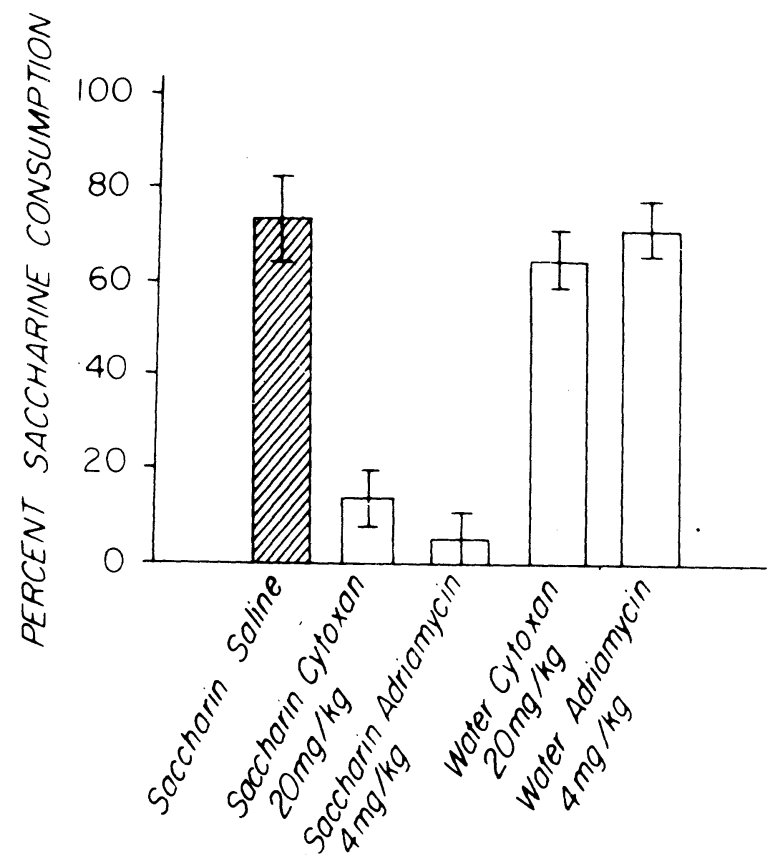

Figure 2. Percent saccharin consumed during two-bottle preference test as a function of conditioning treatment. Mean total fluid consumption during the preference test was: saccharin-saline $=20.0 \mathrm{ml}$; saccharin-Cytoxan $=16.3 \mathrm{ml}$; saccharin-Adriamycin $=15.0 \mathrm{ml}$; water-Cytoxan $=22.5 \mathrm{ml}$; water-Adriamycin $=$ $16.8 \mathrm{ml}$. 
ferences in saccharin preference between the three control and two experimental groups is significant $(p<.01)$. These results indicate that the reduction in preference seen in the experimental groups is not a nonspecific effect of drug treatment.

\section{Discussion}

A number of commonly used antitumor drugs were evaluated for their ability to act as USs in a taste-aversion conditioning paradigm. Dosages selected were based on those in clinical use, although conversions based on species-specific drug metabolism were not attempted. Results were, with one exception, consistent with the idea that drugs which induce nausea and vomiting in humans (i.e., Cytoxan, Adriamycin) produced significant aversions in rats. The observation that cytosine arabinoside, unlike the other GI toxic drugs, did not produce significant aversions is probably due to a species difference between rat and human in metabolism of this drug. Lenaz and Philips (1970) and others (Wodinsky \& Kessler, 1965) have reported that cytosine arabinoside is less toxic in the rat than in other species due to its incomplete phosphorylation in the rat. All three drugs were associated with aversions in humans (Bernstein, 1978).

Vincristine, which does not produce nausea, did not produce saccharin aversions. This is consistent with studies in humans (Bernstein, 1978; Bernstein, Wallace, Bernstein, Bleyer, Chard, \& Hartman, 1979), where control patients receiving Vincristine did not develop taste aversions. A number of drugs which do not produce nausea have been reported to produce conditioned taste aversions (Gamzu, 1977), indicating that GI toxicity may be a sufficient, but not a necessary, condition for the establishment of taste aversions. It is possible that larger doses of Vincristine would produce significant aversions without GI toxicity.

\section{EXPERIMENT 2}

In order to determine whether tumor growth interacts with taste aversion conditioning, rats with transplantable tumors were exposed to a conditioning procedure like the one in Experiment 1.

\section{Method}

Two polyoma virus-induced sarcomas (PW-739 and PW-7410) were used; these tumors grow progressively and are lethal to animals in 8-10 weeks. These two tumors produce different effects on food intake and body weight. The growth of the PW-739 tumor is associated with considerable anorexia and weight loss, while the PW-7410 tumor does not appear to induce reductions of food intake or weight (Bernstein, Samson, \& Sigmundi, Note 1).

Experiment 2a. Fifty-four naive, syngeneic W/Fu female rats were divided randomly into three groups. All rats had a small $(2 \times 2 \mathrm{~cm})$ patch of skin exposed on their right flanks. The tumorfree control rats were injected subcutaneously in this patch with $.01 \mathrm{ml}$ of physiological saline. Experimental rats received .1-ml

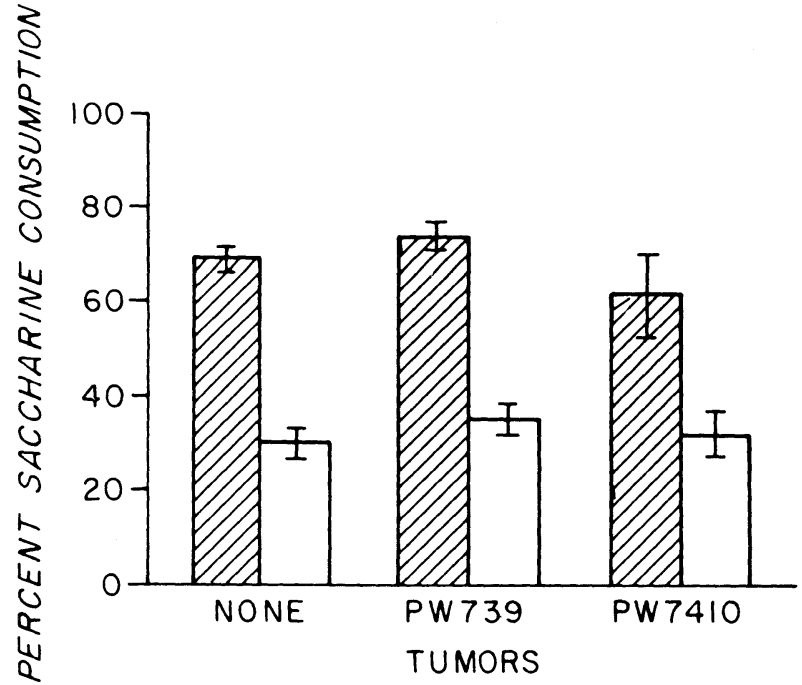

Figure 3. Percent saccharin consumed during two-bottle preference test as a function of tumor and drug treatments. Open bars are Cytoxan treated groups; striped bars are saline controls. Mean total fluid consumption during test: no tumor-Cytoxin $=16.5 \mathrm{ml}$; no tumor-saline $=14.2 \mathrm{ml} ; 739$ tumor-Cytoxan $=$ $15.3 \mathrm{ml} ; 739$ tumor-saline $=19.2 \mathrm{ml} ; 7410$ tumor-Cytoxan $=$ $16.7 \mathrm{ml} ; 7410$ tumor-saline $=\mathbf{1 5 . 3} \mathrm{ml}$.

subcutaneous injections of either PW-7410 or PW-739 tumor cells in a saline solution at a concentration of $10^{6}$ cells $/ \mathrm{ml}$.

Following injection, the animals were given unrestricted access to Purina Rat Chow and water for approximately 6 weeks while the tumors grew. The animals were then housed individually, and the habituation and conditioning procedures described in Experiment 1 were followed. On Day 13, the control (no tumor), PW-739, and PW-7410 groups were each randomly divided in half. Immediately following the 30-min exposure to saccharin solution, one-half of the rats in each group received $.1 \mathrm{ml}$ of physiological saline and the remaining half received Cytoxan $(20 \mathrm{mg} / \mathrm{kg}$ ). On Day 14, all groups received a two-bottle preference test as described in Experiment 1.

Experiment 2 b. Experiment $2 \mathrm{a}$ was essentially repeated with an additional $54 \mathrm{~W} / \mathrm{Fu}$ female rats, but these animals were studied at an earlier stage of tumor growth and with Adriamycin $(4 \mathrm{mg} / \mathrm{kg})$ replacing Cytoxan. Conditioning took place after 4 weeks of tumor growth.

\section{Results}

Experiment 2a. A number of tumor-bearing animals died before testing so final group sizes were: 739-control $(\mathrm{N}=5)$, 739-Cytoxan $(\mathrm{N}=6), 7410$-control $(\mathrm{N}=3), 7410$-Cytoxan $(\mathrm{N}=3)$, no tumor-control $(N=6)$, no tumor-Cytoxan $(N=6)$. Saccharin preference during testing is depicted in Figure 3. Cytoxantreated groups had a preference for water, while saline-treated animals preferred saccharin in the twobottle choice test. An analysis of a factorial experiment with unequal ns for various treatments (Edwards, 1972 , p. 220) yielded a significant overall treatment effect $[F(5,23)=5.13, p<.005]$ and a significant drug effect $[F(1,23)=24.8, p<.005]$. Tumor effects and tumor-drug interactions were not significant $(F<1.0)$. Total fluid consumption of tumorbearing animals did not differ from controls. 


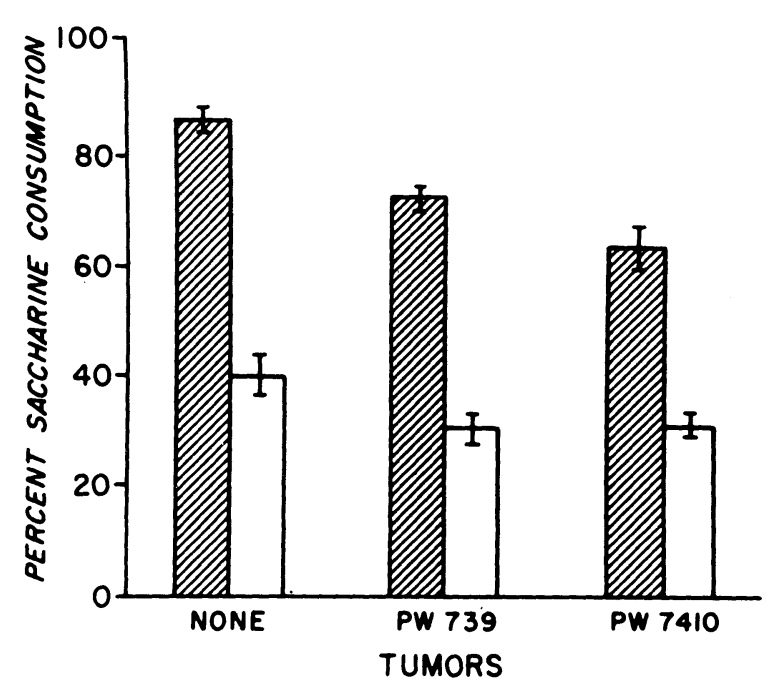

Figure 4. Percent saccharin consumed during two-bottle preference test as a function of tumor and drug treatments. Open bars are Adriamycin-treated groups, striped bars are saline controls. Mean total fluid consumption during test: no tumor-Adriamycin $=17.2 \mathrm{ml}$; no tumor-saline $=\mathbf{2 0 . 2} \mathrm{ml} ; \mathbf{7 3 9}$ tumor-Adriamycin $=15.6 \mathrm{ml} ; 739$ tumor-saline $=\mathbf{2 1 . 9} \mathrm{ml} ; \mathbf{7 4 1 0}$ tumor-Adriamycin $=16.2 \mathrm{ml} ; 7410$ tumor-saline $=20.7 \mathrm{ml}$.

Experiment 2b. Final group sizes for this study were: 739-control $(\mathrm{N}=8)$, 739-Adriamycin $(\mathrm{N}=7), 7410$ control $(\mathrm{N}=8), 7410$-Adriamycin $(\mathrm{N}=9)$, no tumorcontrol $(\mathrm{N}=6)$, no tumor-Adriamycin $(\mathrm{N}=6)$. Results of saccharin preference testing are depicted in Figure 4. As in Experiment 2a, overall treatment effects $[F(5,38)=7.86, p<.005]$ and drug effects $[F(1,38)$ $=34.4, \mathrm{p}<.005]$ were highly significant. Tumor effects $[F(2,38)=1.86, p<.25]$ and tumor-drug interactions $(F<1.0)$ were not significant.

These results replicate the findings reported in Experiment 1 that Cytoxan and Adriamycin are effective unconditioned stimuli in the establishment of conditioned aversions to saccharin. They further indicate that tumor growth does not appear to have an effect on the magnitude of learned aversions.

\section{Discussion}

These studies examined the effect of a chronic disease state (advanced tumor growth) on the acquisition of conditioned taste aversions. Tumor growth is associated with a variety of physiological (Costa, 1977) and behavioral (Bernstein et al., Note 1; Morrison, 1976) effects, including enlargment of spleen and adrenals, anorexia, and activity depression. Yet rats bearing moderate and advanced tumors were comparable to healthy controls in their formation of conditioned taste aversions. Therefore, the chronic malaise produced by a growing tumor neither attenuated nor exaggerated the taste aversions induced by Cytoxan or Adriamycin injections. It is possible that more sensitive tests would reveal effects of tumor growth on this learning.
These findings are important in interpreting the results of human clinical studies. The toxic nature of the USs employed in taste aversion conditioning studies have precluded controlled experimental investigation of this learning in healthy human subjects. Since cancer patients are frequently exposed to these treatments as therapy they are appropriate subjects for examining the acquisition of learned taste aversions in humans. These patients have been shown to have a strong propensity to form conditioned taste aversions to familiar as well as novel foods (Bernstein, 1978; Bernstein et al. 1979; Bernstein \& Webster, Note 2) even when they have received many drug preexposures. Whether results of these studies generalize to healthy humans depends on whether their disease state interacts with taste-aversion learning. Although not conclusive, the studies reported here suggest that tumor growth does not amplify tasteaversion learning. Anecdotal evidence (Garb \& Stunkard, 1974) would also tend to support the conclusion that susceptibility to forming conditioned taste aversions is a characteristic of humans, in general, and not just cancer patients.

\section{REFERENCE NOTES}

1. Bernstein, I. L., Samson, H. H., \& Sigmundi, R. A. The effects of two transplantable polyoma virus-induced sarcomas on food intake of the rat. Submitted for publication, 1979.

2. Bernstein, I. L., \& Webster, M. M. Learned taste aversions in humans. Submitted for publication, 1979.

\section{REFERENCES}

Bernstein, I. L. Learned taste aversions in children receiving chemotherapy. Science, 1978, 200, 1302-1303.

Bernstein, I. L., Wallace, M. J., Bernstein, I. D., Bleyer, W. A., Chard, R. L., \& Hartman, J. R. Learned food aversions as a consequence of cancer treatment. In J. van Eys, M. S. Seelig, \& B. L. Nichols (Eds.), Nutrition and cancer. New York: Spectrum, 1979.

Costa, G. Cachexia, the metabolic component of neoplastic diseases. Cancer Research, 1977, 37, 2327.

EDWARDS, A. L. Experimental design and psychological research. New York: Holt, Rinehart \& Winston, 1972.

ELKINS, R. L. Bait-shyness acquisition and resistance to extinction as function of US exposure prior to conditioning. Physiological Psychology, 1974, 2, 341-343.

GAmzU, E. The multifaceted nature of taste aversion including agents: Is there a single common factor? In L. M. Barker, M. R. Best, \& M. Domjan (Eds.), Learning mechanisms in food selection. Waco, Texas: Baylor University Press, 1977.

Garb, J. L., \& Stunkard, A. J. Taste aversions in man. American Journal of Psychiatry, 1974, 131, 1204-1207.

Garcia, J., Ervin, F. R., \& Koelling, R. A. Bait-shyness: A test for toxicity with $\mathrm{N}=2$. Psychonomic Science, 1967, 7, 245-246.

Garcia, J., Hankins, W. G., Robinson, H. H., \& Vogt, J. L. Bait shyness: tests of CS-US mediation. Physiology \& Behavior, 1972, 8, 807-810.

Goodman, L. S., \& Gilman, A. (EDs.). The pharmacological basis of therapeutics. New York: Macmillan, 1970.

Goudie, A. J., Taylor, M., \& Atherton, H. Effect of prior drug experience on the establishment of taste aversion in rats. Pharmacology Biochemistry and Behavior, 1975, 3, 947-952. 
Lenaz, L., \& Phillips, F. S. Effects of arabinosylcytosine nucleosides on DNA synthesis in rats. Cancer Research, 1970, 30, 1961-1962.

MorRISON, S. D. Control of food intake in cancer cachexia: A challenge and a tool. Physiology \& Behavior, 1976, 17, 705-714.

Riley, A. L., \& Baril, L. L. Conditioned taste aversions: A Bibliography. Animal Learning \& Behavior, 1976, 4, IS-13S.

Wilcoxin, H. C., Dragoin, W. B., \& Kral, P. A. Illness- induced aversions in rats and quail: Relative salience of visual and gustatory cues. Science, 1971, 171, 826-828.

Wodinsky, I., \& Kessler, C. J. Activity of cytosine arabinoside (NSC-63878) in a spectrum of rodent tumors. Cancer Chemotherapy Reports, 1965, 47, 65-68.

(Received for publication November 7, 1979; revision accepted December 20, 1979.) 